\title{
KAJIAN JASA TRAVEL JURUSAN PALANGKARAYA-SAMPIT DITINJAU DARI BIAYA OPERASIONAL KENDARAAN PENUMPANG
}

\author{
Fitri Wulandari $^{(1)}$, Nirwana Puspasari ${ }^{(2)}$ \\ Alumni Fak.Teknik UM Palangka Raya ${ }^{(1)}$ \\ Program Studi Teknik Sipil UM Palangka Raya ${ }^{(2)}$
}

\begin{abstract}
ABSTRAK
Transportasi merupakan peranan yang penting pada aspek kegiatan ekonomi sosial dan budaya. Dilihat dari distribusi keluar masuknya arus penumpang transportasi darat jurusan Palangkaraya-Sampit merupakan jasa travel yang paling diminati sebab waktu tempuh lebih cepat dan efisien. Tujuan penelitian adalah untuk mengetahui besarnya biaya operasional kendaraan, pendapatan, tarif dan Fare Box Ratio (FBR) dari perusahaan jasa travel CV. Sumertha Sari Jurusan Palangkaraya-Sampit.

Metode pengumpulan data penumpang dan analisis untuk data armada adalah metoda pengambilan sampel semesta, mengumpulkan data primer dan sekunder, biaya operasional kendaraan dianalisis dengan metoda pendekatan biaya per kilometer yang dikeluarkan setiap kendaraan, pendapatan dianalisis dengan metoda pendekatan jumlah pendapatan rata-rata perusahaan per tahun dan dikurang dengan total biaya operasional kendaraan (BOK) per kilometer, tarif dianalisis dengan metoda menjumlahkan komponen biaya tetap, biaya tidak tetap dan biaya overhead dalam satuan/pnp (per penumpang) dan Fare Box Ratio (FBR) dianalisis dengan metoda perbandingan nilai Biaya operasional kendaraan (BOK)/tahun dengan pendapatan per tahun.

Dari hasil penelitian diperoleh hasil sebagai berikut: besar biaya operasional (BOK) pada perusahaan CV. Sumertha Sari adalah sebesar Rp. 760.460.275,81/tahun pendapatan yang didapatkan oleh perusahaan CV. Sumertha Sari sebesar Rp. 1.669.000.000,00/tahun, tarif yang didapatkan dari hasil perhitungan adalah sebesar Rp. 50.092,60/penumpang dan hasil Fare Box Ratio (FBR) yang didapatkan dari hasil perhitungan adalah 2,20 dimana hasil FBR > 1 menunjukkan bahwa perusahaan mendapatkan keuntungan dari jasa travel yang dilakukan.
\end{abstract}

Kata kunci: Biaya Operasional Kendaraan, Pendapatan, Tarif dan Fare Box Ratio (FBR). 


\section{PENDAHULUAN}

\section{Latar belakang}

Transportasi merupakan suatu kegiatan yang sangat penting dalam kehidupan masyarakat Kota Palangka Raya dengan jumlah penduduk yaitu 273.428 jiwa dari sensus tahun 2014. Kota Palangka Raya merupakan Ibu Kota Provinsi Kalimantan Tengah, dengan adanya kegiatan perkotaan, transportasi merupakan salah satu penentu kegiatan ekonomi, sosial dan budaya.

Seiring dengan bertambahnya jumlah penduduk dari tahun ke tahun maka kebutuhan terhadap sarana transportasi dengan sendirinya juga semakin meningkat. Letak Kota Palangka Raya yang cukup strategis dalam wilayah Provinsi Kalimantan Tengah menjadikan Kota Palangka Raya sebagai pusat distribusi masuknya penumpang transportasi darat. Pergerakan arus penumpang tersebut berpengaruh pada meningkatnya permintaan sarana angkutan untuk kehidupan sehari-hari dan karena minimnya angkutan massal seperti halnya bus dan angkutan darat sejenisnya maka dirasa perlu untuk menambah moda transportasi umum lainnya berupa Jasa Travel yang mampu menjangkau tujuan lebih luas dan memiliki armada yang lebih banyak sehingga mampu melayani kebutuhan masyarakat akan moda transportasi ini.

Keunggulan dari travel adalah penumpang bisa di jemput di tempat dia berangkat dan bisa di antar ke tempat tujuan dia berada (rumah) door to door, berbeda dengan angkutan umum bus yang tidak bisa menjemput penumpang dari tempat dia berangkat dan hanya bisa mengantar penumpang ke kota tujuannya saja serta hanya bisa menurunkan penumpang di pangkalan bus atau terminal. Dengan keunggulan travel ini penumpangakan lebih senang di jemput dari tempat dia berangkat dan di antar ke tempat tujuannya sebab akan lebih menghemat biaya perjalanan, daripada harus berangkat ke pangkalan atau terminal dan mengeluarkan biaya tambahan, seperti halnya naik ojek atau taksi menuju pangkalan jasa tersebut. Keunggulan dari travel inilah yang menyebabkan masyarakat lebih banyak memilih jasa travel dibandingkan jasa angkutan umum seperti bus.

Adanya layanan travel dengan rute Palangka Raya-Sampit ini dirasa sangat membantu masyarakat dalam memenuhi kebutuhan akan tingginya permintaan layanan transportasi darat, terlebih mengingat bahwa Kabupaten Sampit merupakan salah satu Kota besar di Kalimantan Tengah dimana terdapat pelabuhan laut yang merupakan salah satu jalur keluar masuknya arus transportasi. Dilihat dari distribusi keluar masuknya arus penumpang transportasi darat jurusan Palangka Raya-Sampit merupakan jasa travel yang paling diminati sebab waktu tempuh lebih cepat daripada transportasi sungai. Dalam penelitian ini mencoba mengkaji Biaya Operasional Kendaraan penumpang Jasa Travel Jurusan Palangkan Raya-Sampit dan mengkaji Tarif Penumpang.

\section{Rumusan Masalah}

Berdasarkan latar belakang diatas, dapat dirumuskan pokok permasalahan yang akan dibahas antara lain:

1. Seberapa besar biaya operasional untuk jasa Travel pada jurusan Palangka Raya-Sampit?

2. Berapakah pendapatan yang didapatkan jasa Travel Jurusan Palangka Raya-Sampit?

3. Berapakah tarifpenumpang jasa Travel Jurusan Palangka Raya-Sampit berdasarkan Biaya Operasional Travel yang dikeluarkan?

4. Bagaimana nilai Fare Box Ratio (FBR) pada Travel Jurusan Palangka Raya-Sampit?

\section{Tujuan Masalah}

Adapun yang menjadi tujuan penelitian adalah:

1. Untuk mengetahui besarnya biaya operasional jasaTravel pada jurusan Palangka Raya-Sampit.

2. Untuk mengetahui pendapatan yang didapatkan jasa Travel Jurusan Palangka Raya-Sampit.

3. Untuk mengetahui tarif penumpang jasa Travel pada jurusan Palangka Raya-Sampit berdasarkan Biaya Operasional Travel yang dikeluarkan.

4. Untuk mengetahui nilai Fare Box Ratio (FBR) pada Travel Jurusan Palangka Raya-Sampit.

\section{KAJIAN PUSTAKA}

\section{Biaya Operasional Kendaraan}

Biaya operasional kendaraan (BOK) adalah suatu lintasan penghasilan untuk keperluan kendaraan dalam perjalaanan.

Komponen biaya operasi kendaraan ini terdiri dari:

a. Biaya tetap (Standing Coast) 
Biaya tetap adalah biaya yang dalam pengeluarannya tetap tanpa tergantung pada volume produksi yang terjadi.

Pada volume produksi yang terjadi. Biaya tetap ini dapat dikelompokkan sebagai berikut:

1) Biaya Modal Kendaraan.

2) Biaya Penyusutan.

3) Perijinan dan administrasi.
a) Biaya ijin usaha
b) Biaya ijin trayek
c) Biaya pengelolaan
d) STNK
e) KIR

4) Asuransi.

5) Awak kendaraan.

a) Gaji sopir

b) Gaji karyawan

6) Cuci mobil.

7) Kampas rem.

8) Kampas kopling.

9) AC.

10) Bahan bakar minyak.

b. Biaya tidak tetap (Running Coast)

Biaya tidak tetap adalah yang secara tidak langsung berhubungan dengan produk jasa yang dihasilkan.

Ditinjau dari kegiatan usaha angkutan, maka biaya yang dikeluarkan untuk suatu produksi jasa angkutan yangakan dijual kepada pemakai jasa dapat dibagi menjadi tiga bagian yaitu:

a. Yang dikeluarkan untuk pengelolaan perusahaan.

b. Yang dikeluarkan untuk operasi kendaraan.

c. Yang dikeluarkan untuk retribusi, iuran, sumbangan dan lain-lain yang berkenaan dengan kepemilikan usaha, kendaraan, dan operasinya.

Biaya tetap ini dapat dikelompokkan sebagai berikut:

1) Biaya ban.

2) Retribusi Parkir

3) Perawatan

a) Servis besar.

b) Servis kecil.

c. Biaya overhead

Biaya overhead adalah biaya yang secara tidak langsung dikeluarkan oleh pemilik kendaraan atau pengusaha angkutan penumpang yang akandipergunakan untuk keperluan biaya operasional kendaraan, dan biaya keperluan kantor lainnya. Berdasarkan PerPres no. 54 pasal 66 menyatakan bahwa biaya overhead yang dianggap wajar bagi penyedia adalah 10 hingga $15 \%$. Namun dalam menentukan persentasi biaya overhead tentunya tergantung dari ketentuan dan keperluan yang ada pada masing-masing penyedia. Dalam penelitian ini diambil angka persentasi maksimal, yaitu 15\% dari total Biaya Operasional kendaraan (BOK).

\section{METODE PENELITIAN}

Dalam pengumpulan data di lapangan penentuan lokasi merupakan hal yang sangat penting karena akan memudahkan proses penelitian.

Pengamatan tersebut dilakukan pada biro perjalanan yang memiliki ijin operasi di Kota Palangka Raya, yaitu pada perusahaan CV. Sumertha Sari.

Sasaran yang diinginkan dalam penentuan lokasi adalah:

a. Analisis aktivitas angkutan travel jurusan Palangka Raya-Sampit.

b. Analisis terhadap Biaya Operasional Kendaraan (BOK).

c. Analisis terhadap pendapatan perusahaan.

d. Analisis terhadap tarif.

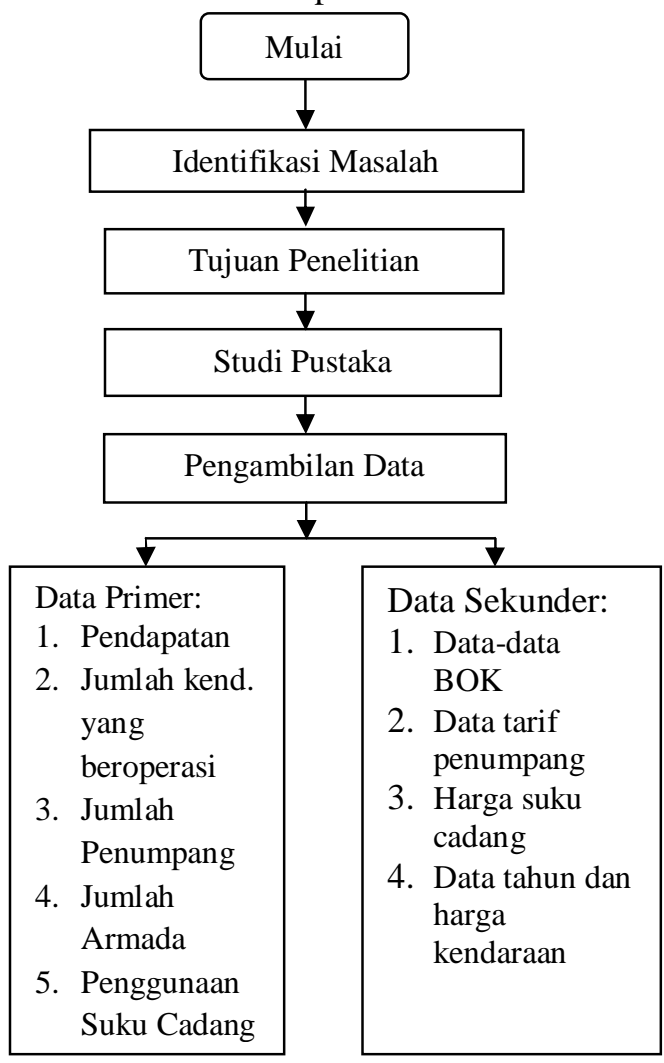




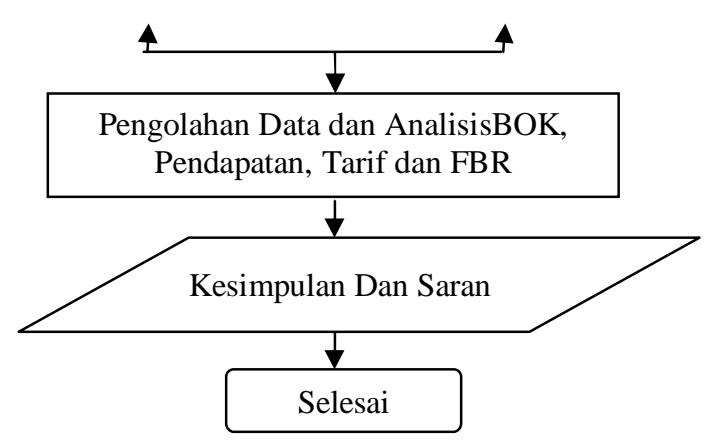

Gambar 3.2 Bagan Alir Penelitian

Pengumpulan data yang dilakukan dalam penelitian ini adalah metoda pengambilan sampel semesta. Adapun yang dimaksud dengan metode ini adalah suatu cara pengumpulan data yang sifatnya menyeluruh, guna mengetahui keadaan yang sebenarnya pada setiap pengguna jasa dan pengusaha jasa angkutan yang berbeda.

\section{Tahapan Penelitian}

a. Mulai dengan memilih latar belakang sebagai pendahuluan, menentukan rumusan masalah, tujuan, batasan dan manfaat penelitian.

b. Studi literatur berupa landasan teori (umum) mengenai angkutan travel, karakteristik travel, angkutan travel, Biaya Operasional Kendaraan (BOK), pendapatan, tarif, fare box ratio.

c. Memilih lokasi penelitian untuk pengamatan terhadap biro perjalanan yang memiliki ijin operasi di kota Palangka Raya.

d. Mengumpulkan data primer dengan metode langsung (konvensional), berupa pendapatan, jumlah kendaraan yang beroperasi, jumlah penumpang, jumlah armada, dan penggunaan suku cadang yang diperoleh melalui observasi, dan interview.

e. Mengumpulkan data sekunder, dengan mengumpulkan data yang didapat dari instansi yaitu Dinas Perhubungan berupa data Biaya Operasional Kendaraan (BOK), data tarif penumpang, harga suku cadang, dan data tahun serta harga kendaraan yang berlaku di Palangka Raya-Sampit dan peraturan yang mengatur sistem transportasi di Palangka Raya-Sampit.

f. Pengolahan data menggunakan analisis Biaya Operasional Kendaraan (BOK), analisis pendapatan, analisis tarif, dan analisis Fare Box Ratio (FBR).
1) Analisis $\mathrm{BOK}$

Analisis biaya operasional kendaraan (BOK) yang adalah jumlah dari semua komponen biaya operasi kendaraan penumpang tersebut pertahun lalu dihitung per'Km'nya.

Komponen biaya operasional kendaraan (BOK) yang dihitung adalah:

Biaya tetap, biaya tidak tetap dan biaya overhead.

2) Analisis Pendapatan

Analisis pendapatan adalah jumlah pendapatan rata-rata perusahaan per tahun dikurang total Biaya Operasional Kendaraan (BOK) kendaraan perusahaan lalu dihitung per'Km'nya. Lalu hasilnya dibandingkan dengan total Biaya Operasional Kendaraan (BOK) per'Km'nya, dan dianalisis apakah pendapatannya memberikan keutungan atau malah kerugian.

Pendapatan yang akan dihitung adalah:

Faktor Load, jumlah penumpang pertahun, pendapatan penumpang pertahun dan operasi kerja dalam setahun.

3) Analisis Tarif

Analisis tarif adalah menjumlahkan komponen biaya tetap, biaya tidak tetap, dan biaya overhead dalam satuan/pnp (per pernumpang) akan di dapat hasil dari total biaya per penumpang lalu dianalisis lebih tinggi atau lebih rendah dibandingkan dengan biaya per penumpang berdasarkan tarif yang telah ditentukan pemerintah.

4) Fare Box Ratio $(F B R)$

Membandingkan nilai BOK pertahun dengan pendapatan pertahun didapatkan nilai FBR. Jika nilai FBR lebih dari 1 maka perusahaan untung dan apabila nilai FBR kurang dari 1 maka perusahaan rugi.

g. Perhitungan data untuk Biaya Operasional Kendaraan (BOK) menggunakan metode pendekatan biaya per kilometer yang dikeluarkan oleh kendaraan. Komponen Biaya Operasional Kendaraan (BOK)ada 3 yaitu:

1) Biaya tidak tetap berupa biaya modal, biaya bunga modal, biaya penyusutan, biaya ijin usaha, biaya trayek, STNK, KIR, asuransi, gaji sopir, gaji karyawan, cuci mobil, kampas rem, kampas kopling, dan AC. 
2) Biaya tidak tetap berupa biaya perbaikan ban, bahan bakar minyak, retribusi parkir, perawatan (servis kecil dan servis besar).

3) Biaya overhead

h. Kesimpulan dari hasil analisis ini,akan diperoleh sejauh mana tingkat kemudahan yang diberikan terhadap penumpang dari besar Biaya Operasional Kendaraan (BOK) oleh penyedia jasa per kilometer.

i. Saran.

j. Selesai.

\section{HASIL DAN PEMBAHASAN}

Berdasarkan jumlah sampel perusahaan yang memiliki ijin trayek angkutan mobil penumpang jurusan Palangka Raya-Sampit setelah interview terhadap pengusaha jasa travel untuk jenis angkutan mobil "Innova", sampel diambil dari jumlah populasi untuk jurusan Palangka RayaSampit.

\section{Tabel 4.5 Rekapitulasi Biaya Operasional} Kendaraan (BOK)

\begin{tabular}{|c|l|c|}
\hline \multirow{2}{*}{ No } & \multicolumn{1}{|c|}{ Keterangan } & $\begin{array}{c}\text { CV. Sumertha } \\
\text { Sari }\end{array}$ \\
\cline { 2 - 3 } & \multicolumn{1}{|c|}{ Biaya } & $\mathbf{( R p / k m )}$ \\
\hline $\mathbf{1 .}$ & Biaya Tetap & $2.040,82$ \\
\hline & Biaya Penyusutan & $2.618,28$ \\
\hline & Biaya Pengelolaan & $3.321,64$ \\
\hline & Gaji Sopir & $1.770,00$ \\
\hline & Gaji Karyawan & 53,15 \\
\hline & Biaya Kampas Rem & 82,37 \\
\hline & Biaya Kampas Kopling & 66,43 \\
\hline & Biaya Ac & 558,03 \\
\hline
\end{tabular}

\begin{tabular}{|c|c|c|c|}
\hline No & Tahun & \multicolumn{2}{|c|}{ Penumpang } \\
\hline 1. & 2014 & \multicolumn{2}{|c|}{17.025} \\
\hline 2. & 2015 & \multicolumn{2}{|c|}{17001} \\
\hline & Jumlah & \multicolumn{2}{|c|}{34.026} \\
\hline & Rata-Rata & \multicolumn{2}{|c|}{17.013} \\
\hline & \multicolumn{2}{|l|}{ STNK } & 118,25 \\
\hline & \multicolumn{2}{|l|}{ KIR } & 21,26 \\
\hline \multicolumn{3}{|c|}{ Total } & $10.650,23$ \\
\hline 2. & \multicolumn{2}{|c|}{ Biaya Tidak tetap } & \\
\hline & \multicolumn{2}{|l|}{ Biaya Ban } & 790,81 \\
\hline & \multicolumn{2}{|c|}{ Biaya Bahan Bakar } & 987,245 \\
\hline & \multicolumn{2}{|c|}{ Biaya Retribusi Parkir } & 398,60 \\
\hline & \multicolumn{2}{|c|}{ Biaya Servis Kecil } & $2.198,86$ \\
\hline & \multicolumn{2}{|c|}{ Biaya Servis Besar } & $2.196,00$ \\
\hline \multicolumn{3}{|c|}{ Total } & $6.571,52$ \\
\hline 3. & \multicolumn{2}{|c|}{$\begin{array}{l}\text { Total Biaya Tetap dan } \\
\text { Tidak Tetap }\end{array}$} & $17.221,74$ \\
\hline
\end{tabular}

\section{Pengolahan Data Biaya Operasional Kendaraan (BOK)}

1. Analisis Biaya Operasi Kendaraan (BOK)Hasil analisis komponen BOK:

Km-tempuh/tahun

$=224 \mathrm{Km} / \mathrm{hr} \times 28$ hari $/ \mathrm{bln} \times 12 \mathrm{bulan} / \mathrm{thn}$

$=75.264 \mathrm{Km} /$ tahun

BOK = Biaya tetap + biaya tidak tetap $=$ Rp. $10.650,23 / \mathrm{km}+\mathrm{Rp} \cdot 6.571,52 / \mathrm{km}$ $=$ Rp. $17.221,74 / \mathrm{km}$

Biaya Overhead

$=$ Jumlah $(\mathrm{BOK}) \times 15 \%$

$=$ Rp. $17.221,74 / \mathrm{km} \times 15 \%$

$=$ Rp. $2 \cdot 583,26 / \mathrm{km}$

Jumlah (BOK)

$=$ Biaya tetap + biaya tidak tetap +

biaya overhead

$=$ Rp. $10 \cdot 650,23 / \mathrm{km}+$ Rp. $6 \cdot 571,52 / \mathrm{km}+$

Rp. $2.583,26 / \mathrm{km}$

$=$ Rp. $19.805,00 / \mathrm{km}$

BOK per kend-km

$=$ Jumlah $(\mathrm{BOK}) \times \mathrm{Km}$-tempuh/tahun

$=$ Rp. $19.805,00 / \mathrm{km} \times 75.264 \mathrm{Km} / \mathrm{tahun}$

$=$ Rp.1.490.603.810,18/tahun

\section{Analisa Pendapatan}

Perhitungan pendapatan dilakukan untuk mengetahui pemasukan dari perusahaan. Data yang diperoleh untuk menghitung pendapatan adalah data jumlah penumpang dan data jumlah keberangkatan untuk mendapatkan faktor load. Perhitungan pendapatan dihitung sebagai berikut:

Tabel 4.6 Jumlah penumpang tahun 2014 dan 2015

a. Pendapatan perusahaan/Tahun

Diketahui:

Jumlah penumpang tahun $2014=17.025$ Penumpang

Jumlah penumpang tahun $2015=17.001$ Penumpang

Harga tiket $=$ Rp.100.000, 
Pendapatan tahun 2014

$=$ Jumlah penumpang/tahun $\mathrm{x}$ harga tiket

$=17.025 \times 100.000$,

$=$ Rp. 1.702.500.000,-/tahun

Pendapatan tahun 2015

$=$ Jumlah penumpang/tahun $\mathrm{x}$ harga tiket

$=17.001 \times 100.000,-$

= Rp. 1.700.100.000,-/tahun

Pendapatan rata-rata selama 2 tahun:

$=\frac{\text { Pendapatan thn 2014 + Pendapatan thn } 2015}{2}$

$=\frac{\mathrm{Rp} \cdot 1 \cdot 702 \cdot 500 \cdot 000,00+\mathrm{Rp} \cdot 1 \cdot 700 \cdot 100 \cdot 000,00}{2}$

$=$ Rp.1.701.300.000,-/tahun

Tabel 4.7 Faktor Load Tahun 2014 dan 2015

Rata-rata penumpang dengan faktor load:

Diketahui:

$\begin{array}{ll}\text { Faktor Load } & =0,72 \\ \text { Kapasitas Penumpang } & =7 \text { orang } \\ \text { Hari Kerja } & =336 \text { hari } \\ \text { Jumlah Armada } & =10\end{array}$

Rata-rata penumpang

$=$ Hari kerja $\mathrm{x}$ Kapasitas pnp $\mathrm{x}$ Jumlah armada $\mathrm{x}$ Faktor load

$=336 \times 7 \times 10 \times 0,72$

$=16.934,4 \mathrm{pnp} /$ tahun

3. Analisis Tarif

Dari rekapitulasi BOK tersebut maka tarif untuk CV. Sumertha Sari didapat sebagai berikut:

a. Tarif pokok per pnp

$$
\begin{aligned}
& =\frac{\mathrm{BOK}}{\text { Kapasitas Penumpang pnp/tahun }} \\
& =\frac{\text { Rp.1.490.603.810,18/ tahun }}{16.934,4 \mathrm{pnp} / \text { tahun }} \\
& =\text { Rp. 88.022,64/pnp }
\end{aligned}
$$

Jadi, tarif dasar Palangka Raya-Sampit adalah:

b. Tarif

$$
\begin{aligned}
& =\text { Tarif Pokok }+(10 \% \text { dari Tarif Pokok }) \\
& =\text { Rp. } 88.022,64 / p n p+(10 \% x \\
& \text { Rp. } 88.022,64 / p n p) \\
& =\text { Rp. } 96.824,46 / p n p
\end{aligned}
$$

4. Analisis Fare Box Ratio $(F B R)$

Diketahui:

a. Pendapatan/tahun = Rp. 1.701.300.000,-/tahun

b. Biaya Operasional kendaraan = Rp. 1.490.603.810,18/tahun

c. $\mathrm{FBR}=\frac{\text { Pendapatan } / \text { tahun }}{\text { BOK/tahun }}$

$$
\begin{aligned}
& =\frac{\text { Rp.1.701.300.000,00/tahun }}{\text { Rp.1.490.603.810,18/tahun }} \\
& =1,14
\end{aligned}
$$

Kesimpulan:

Jika, FBR > 1 = Untung

Jika, FBR $<1=$ Rugi

\begin{tabular}{|c|c|c|}
\hline No & Tahun & Faktor Load \\
\hline 1. & 2014 & 0,72 \\
\hline 2. & 2015 & 0,72 \\
\hline & Jumlah & $\mathbf{1 , 4 5}$ \\
\hline & Rata-Rata & $\mathbf{0 , 7 2}$ \\
\hline
\end{tabular}

Hasil FBR yang didapat:

Hasil FBR yang didapat:

$1,14>1=$ Perusahaan mendapatkan keuntungan.

Jadi nilai $F B R$ untuk perusahaan $\mathrm{CV}$. Sumertha Sari adalah 1,14 dan perusahaan tersebut mendapatkan keuntungan.

\section{KESIMPULAN DAN SARAN}

\section{Kesimpulan}

Berdasarkan hasil pembahasan pada bab empat dapat diambil kesimpulan sebagai berikut:

a. Besar Biaya Operasional Kendaraan (BOK) pada perusahaan CV. Sumertha Sari jurusan Palangkaraya-Sampit per-tahun adalah sebesar Rp. 1.490.603.810,18/tahun.

b. Dari hasil perhitungan data pendapatan CV. Sumertha sari jurusan Palangkaraya-sampit per-tahun didapat Rp. 1.701.300.000,00/tahun.

c. Tarif harga perusahaan CV. Sumertha Sari jurusan Palangka Raya-Sampit yang 
didapatkan dari hasil perhitungan adalah sebesar Rp. 96.824,46 per-penumpang.

d. Dari hasil perhitungan tarif dan pendapatan perusahaan berdasarkan pendekatan Biaya Operasional Kendaraan (BOK) maka tarif yang diperoleh adalah Rp. 96.824,46/pnp, jika dibandingkan dengan tarif yang berlaku saat ini yaitu sebesar Rp.100.000,00/pnp, maka tarif yang berlaku sekarang sangat ideal dari hasil perhitungan $\mathrm{BOK}$.

e. Hasil perhitungan Fare Box Ratio (FBR) pada perusahaan CV. Sumertha Sari adalah 1,14, yaitu hasil FBR > $1(1,14>1)$ menunjukkan bahwa perusahaan mendapatkan keuntungan dari jasa travel yang dilakukan.

\section{Saran}

Berdasarkan kesimpulan yang diperoleh dari hasil penelitian, maka dapat diberikan beberapa saran sebagai berikut:

a. Jika dilihat dari Biaya Operasional Kendaraan (BOK) maka dapat disimpulkan bahwa tarif jasa angkutan Rp.100.000,-/penumpang untuk jurusan Palangkaraya-Sampit dirasa sudah sangat ideal dengan BOK yang dikeluarkan dari pihak travel. Untuk itu disarankan kepada para pengusaha jasa angkutan travel untuk mempertahankan kualitas pelayanan terhadap penumpang dan pengguna jasa travel.

b. Mengingat besarnya biaya operasional yang dikeluarkan oleh pihak perusahaan penyedia jasa travel, maka untuk menekan pengeluaran maka dapat dilakukan beberapa langkah penekanan biaya pengeluaran yang kelak akan berimbas kepada besarnya keuntungan yang didapat. Salah satunya adalah pengurangan frekwensi pencucian mobil ke salon mobil yang biasanya dilakukan per-3 hari menjadi 4 hari sekali, selebihnya pencucian mobil dapat dilakukan dirumah tergantung pada kondisi mobil tersebut.

c. Mengingat persaingan dalam bisnis travel tergolong ketat, maka disarankan kepada pihak pengusaha travel agar dapat mempertahankan atau bahkan meningkatkan pelayanan terhadap penumpang travel, demi kelangsungan bisnis travel yang notabene bergantung pada kepuasan dan antusiasme penumpang.

\section{DAFTAR PUSTAKA}

Abubakar, Iskandar, dkk, 1996, Menuju Lalu Lintas dan Angkutan Jalan Yang Tertib, Direktorat Perhubungan Darat.

Astira, Imron, Taufik A.G, dan Betty Susanti, 2007, Pedoman Pelaksanaan Kerja Praktek dan Tugas Akhir (Skripsi). Penerbit Jurusan Teknik Sipil Universitas Sriwijaya, Inderalaya.

Direktorat Jendral Perhubungan Darat, 1993, Peraturan Pemerintah Republik Indonesia Nomor 42 Tentang Angkutan Jalan, Departemen Perhubungan, Jakarta.

Direktorat Perhubungan RI, 1999, Keputusan Menteri Perhubungan No. KM 84 Tahun 1999, Penyelenggaraan Angkutan Orang Di Jalan Dengan Kendaraan Umum. Departemen Perhubungan Republik Indonesia. Jakarta.

Direktorat Jenderal Perhubungan Darat, 2001, Keputusan Direktur Jenderal Perbuhungan Darat Nomor. SK.653/AJ.202.DRJD/2001 Tentang Petunjuk Teknis Penyelenggaraan Angkutan Sewa, Departemen Perhubungan Republik Indonesia. Jakarta.

Direktorat Bina Teknik, Direktorat Jenderal Bina Marga, 2001, Biaya Operasi Kendaraan (BOK) Untuk Jalan Perkotaan Di Indonesia. Departemen Pekerjaan Umum, Jakarta.

Endrayanto Poly Sujarweni V.Wiratna, 2012, Statika Untuk Penelitian, Edisi Cetakan Pertama, Graha Ilmu, Jogyakarta.

Khristy, C Jotin, and B Kent Lall, 2003, Dasardasar Rekayasa Tranportasi. Penerbit Erlangga, Jakarta.

Morlok, 1982. Pengantar Teknik dan Perencanaan Transportasi, Erlangga, Jakarta. 
Kajian Jasa Travel Jurusan Palangka Raya-Sampit..., Fitri. W/Nirwana. P

KM 84, 1999, Penyelenggaraan Angkutan Orang Di Jalan Dengan Kendaraan Umum, Jakarta.

Rosga, E.A dab S.I. Hartini, 1999, Analisa Biaya Pemilik Dan Operasional Kendaraan Angkutan Antar Kota di Kalimantan Tengah, tidak di publikasikan.

Tamin, O.Z 2000, Perencanaan dan Permodelan Transportasi, Edisi kedua, ITB, Bandung. 